\title{
REVIEW
}

\section{Claims for the anabolic effects of growth hormone: a case of the Emperor's new clothes?}

\section{J Rennie}

Br J Sports Med 2003;37:100-105

This review examines the evidence that growth hormone has metabolic effects in adult human beings. The conclusion is that growth hormone does indeed have powerful effects on fat and carbohydrate metabolism, and in particular promotes the metabolic use of adipose tissue triacylglycerol. However, there is no proof that net protein retention is promoted in adults, except possibly of connective tissue. The overexaggeration of the effects of growth hormone in muscle building is effectively promoting its abuse and thereby encouraging athletes and elderly men to expose themselves to increased risk of disease for little benefit.

Correspondence to: Professor Rennie, Division of Molecular Physiology, Faculty of Life Sciences, Old Medical School, University of Dundee, Dundee DDI 4HN,

Scotland, UK

m.j.rennie@dundee.ac.uk

Accepted

2 December 2002
A search of the internet for the words "growth hormone" will bring up a large number of hits, and most of these have very little to do with the actual physiology or pharmacology of growth hormone $(\mathrm{GH})$ or the recombinant form manufactured as a drug (rhGH). Instead, the search engine will identify a large number of URLs leading to web pages, most of which promote $\mathrm{GH}$ as either a rejuvenating agent for middle aged and elderly men and women or as a muscle building agent for body builders and athletes. The link between the two is the widespread supposition that administration of exogenous $\mathrm{GH}$ will build muscle mass in adult humans. Some web sites advocate the use of GH itself. True pharmaceutical grade human GH (hGH) preparations are available for self administration after registration in the United States as a patient in one of many online clinics, or by making a trip into Mexico from the United States. Black market also widely available in the body building and professional athletic communities. Nasal sprays (of doubtful efficacy) are available from many online suppliers, as are nutritional supplements claimed (on no visible evidence) to cause anabolism indirectly, as a result of increased GH secretion. Examples of the claims made are shown below: "Product $\mathrm{X}$ is a high concentration real Pharmaceutical Grade Recombinant Human Growth Hormone solution (2040 ng/ml.) The product comes with a patented delivery system, that really works allowing complete HGH absorption and in raising IGF-I levels and restoring total youthful homeostasis. Recent double blind clinical studies have shown a 30\% increase in IGF-I levels after just one month of use with Product $\mathrm{X}$ and over $110 \%$ increase after just six months of use". For GH releasers, typical claims include: injectable rhGH-some of cadaveric origin-is
"Product Y contains the human unique growth hormone releasing formula used in the famous Rome experiments. For many users this synergistic combination of Arginine, Pyroglutamate and Lysine is the most potent HGH releaser, dramatically raising IGF-I levels for a solid eight hours after use! The low price and great results has made Product Y the HGH product of choice for many anti-aging programs." Or: "Our proprietary formula-Product Z-will naturally "kick start" your pituitary gland providing everything it needs to restore HGH pulses to youthful levels! When this happens your body then has the IGF-I it needs for tissue, bone and muscle repair-this is why some call it "turning back the clock." And: "Product $\mathrm{Z}$ is the best product to achieve very rapid increases in human growth hormone levels. It is also a favorite among body builders." None of the claims made can be substantiated by publications in the peer reviewed literature, usually because the companies do not cite the papers, and, when they do, the papers are of poor quality. There are a large number of problems here, but the one of most concern is the extent to which the scientific and medical community interested in sports is effectively promoting the use of a substance with potentially severe side effects by uncritically accepting the proposition that GH is anabolic in healthy adults. This proposition is actually reinforced by efforts to justify the development of methods to detect exogenous GH in human body fluids-for example, the IOC/EC sponsored GH2000 study-and by, for example, describing GH as "the most anabolic substance known", as was claimed in the publicity for the recent UK Royal Society of Chemistry sponsored conference on drugs in sport (http://www.rsc.org/ pdf/confs/symp230502.pdf).

In fact, as is argued below, the evidence that $\mathrm{GH}$ is anabolic in healthy adults is very poor. Furthermore, there is good evidence that chronic high serum concentrations of $\mathrm{GH}$ decrease performance and acutely may even cause metabolic changes in the short term that are likely to diminish the capacity for strenuous physical activity. Perhaps most worryingly, high dose chronic hGH administration in normal adults may lead to metabolic alterations that are associated with a number of deleterious side effects such as cardiac instability, hypertension, and the development of insulin resistance and possibly type 2 diabetes, many of which are suffered by

Abbreviations: $\mathrm{GH}$, growth hormone; $r \mathrm{GH}$, recombinant human growth hormone; IGF-I, insulin-like growth factor I 
patients who produce excess growth hormone as a result of pituitary tumours - that is, acromegaly-and by patients receiving rhGH in an attempt to combat wasting caused by HIV/AIDS

\section{GH SECRETION}

$\mathrm{GH}$ is secreted in a pulsatile fashion from the anterior hypophysis, beneath the hypothalamus in the brain. As a result of alternative splicing and proteolytic processing, a number of different immunoreactive species, are secreted into the blood. 'The relative efficacy of the binding of each molecular species to the GH receptors and the extent of the subsequent physiological and pharmacological effects are known for only the major forms of the hormone and are almost certainly not uniform. ${ }^{12}$ During human development, $\mathrm{GH}$ secretion is maximal during periods of growth, most obviously adolescence; thereafter both the periodicity and amplitude of GH secretion falls at a relatively low rate-for example, the total amount of GH secreted by a 60 year old man each day may be about half that secreted by a 20 year old. ${ }^{3} \mathrm{GH}$ secretion usually occurs nocturnally, ${ }^{4}$ but may be stimulated during the day by high protein foods, especially those containing arginine, ${ }^{5}$ and by exercise of both the aerobic and resistance types. ${ }^{6-9}$ Apart from sleep, exercise is the most potent physiological stimulus of GH secretion, and, although it is well characterised, the underlying mechanisms and its telenomic role are still largely unknown. The extent of the exercise induced stimulation of $\mathrm{GH}$ secretion appears to be proportional to the intensity of exercise ${ }^{10}$ because of alterations in amplitude of secretory pulses. Women appear to secrete more GH than men at the same intensity of exercise. ${ }^{11}$ Preceding exercise sensitises GH secretion, so that repeated exercise results in a greater response per bout. ${ }^{12}$ The total amount of GH secretion tends to be greater with moderate dynamic exercise than with resistance exercise, ${ }^{8}$ possibly simply because it continues longer. These two characteristics are inconsistent with $\mathrm{GH}$ being responsible for an adaptive response in muscle bulk because women have less muscle than men and aerobic exercise is associated with alterations in muscle composition not bulk. Obesity and aging also diminishes normal GH secretion and the response to stimuli such as arginine and clonidine. ${ }^{313}{ }^{14}$ The ability to increase GH with exercise is diminished with obesity and aging, ${ }^{9}{ }^{15}$ but is certainly not abolished in either case.

\section{METABOLIC EFFECTS OF GH}

This area has been recently reviewed. ${ }^{16}$ Most of the anabolic effects of GH are not direct metabolic effects on target tissues such as muscle, but are in fact the result of increased production of insulin-like growth factor I (IGF-I) from the liver (as a consequence of which the serum concentration of IGF-I is increased) as well as the production of IGF-I in tissues that are responsive to $\mathrm{GH}$ such as bone and muscle. ${ }^{17}$ In growing animals, in children, and in adults with GH deficiency, GH is very anabolic, causing increases in bone and muscle mass. ${ }^{18-20}$

GH probably stimulates the hypertrophy of muscle in young animals and children, as a result of IGF-I stimulation of (a) amino acid transport, ${ }^{21} 22(b)$ the translational stage of protein synthesis, ${ }^{22}$ and (c) gene transcription, ${ }^{23}$ all actions appropriate to tissue building. It also stimulates the growth of the long bones as a result of increasing osteoblast activity in the postepiphyseal region of bones that have not yet fused. ${ }^{18}$

In addition to its effects mediated by IGF-I, GH greatly stimulates lipolysis in adipose tissue, ${ }^{24}$ both central and peripheral, by an IGF-I independent mechanism. The effects of free fatty acids in inhibiting uptake of glucose into heart, adipose tissue, and muscle are at least partly responsible for the hyperglycaemia and insulin resistance associated with rhGH administration. ${ }^{25}{ }^{26} \mathrm{GH}$ inhibits glycogen storage in liver and muscle ${ }^{27}$ by a mechanism that lies beyond the insulin receptor. ${ }^{26}$ Somewhat paradoxically, IGF-I alone has an acute insulin-like hypoglycaemic effect. ${ }^{28}$ However, this effect appears to be usually overridden during chronic rhGH treatment. ${ }^{29}$

Furthermore, GH causes increased water absorption by the gut and increased sodium retention probably by activation of the renin-angiotensin system..$^{30-32}$ This can lead to extracellular fluid accumulation and, in some cases, also to carpal tunnel syndrome as well as elevated blood pressure at high doses.

\section{GH AS AN ANABOLIC AID IN GROWTH DEFICIENT STATES}

There is no doubt whatsoever that exogenous GH (nowadays always rhGH) can have a considerable beneficial effect in restoring growth in GH deficient children and short, apparently normal children, children with kidney disease, and babies born when short for gestational age. ${ }^{33-37}$ In true GH deficiency and renal disease, treatment results in a greater final height, but in idiopathic short stature or in children who are short for gestational age, the benefit seems to be confined to accelerating growth, not increasing the final height achieved. The accelerated growth is associated with rapid increases in energy expenditure and protein turnover, as expected. ${ }^{19} 3839$

The administration of rhGH to patients suffering from sepsis and trauma, although hailed as a way of controlling the pronounced wasting observed in such patients, is now rare, after a first flush of enthusiasm in the mid to late 1990s. ${ }^{41}$ This is because in a large multicentre trial of rhGH in patients in intensive care units, there was a substantial excess mortality associated with the treatment group. ${ }^{39}{ }^{42}$ The reason has never been adequately identified, but one strong possibility is cardiac instability precipitated by elevated plasma free fatty acid concentrations resulting from the lipolytic effect of GH. The use of rhGH in such circumstances is now regarded as risky.

In elderly subjects who are GH deficient, short term administration of rhGH or IGF-I increases the rate of muscle protein synthesis. ${ }^{43}$ Chronic administration of rhGH was reported to reduce body fat and also increase lean body mass-that is, irrespective of fat loss-in GH deficient men. ${ }^{44-47}$ One of the odd features of this work is that no changes in quadriceps muscle fibre area or fibre type or distribution of fibre types were associated with the reported increase in lean body mass despite claimed increases in thigh muscle cross sectional area measured by computed $x$ ray tomography.

The use of rhGH in patients with wasting caused by HIV/AIDS has grown dramatically in the past 10 years, ${ }^{29}$ but evidence of efficacy in regrowing or even maintaining muscle is as yet lacking.

\section{EFFECTS OF rhGH ON MUSCLE HYPERTROPHY AND MUSCULAR PERFORMANCE IN YOUNG AND OLD HEALTHY SUBJECTS}

It has been speculated that the increased GH secretion in humans would serve as an anabolic signal to increase muscle mass and upregulate the adaptations that occur with exercise training. This hypothesis is supported by the results of many animal studies, in which GH administration causes substantial increases in both muscle mass and strength. In these studies, however, the animals involved were probably still growing and sensitive to both GH and IGF-I.

Acute administration of rhGH or IGF-I in normal healthy humans in the postabsorptive state is reported to acutely increase forearm net balance of amino acids. ${ }^{48}{ }^{49}$ The effects are claimed to occur through the stimulation of protein synthesis rather than a fall in protein breakdown. No similar studies were carried out in the fed state, and the lack of reports of any longer term effects (see below) seems to suggest that this 
anabolic stimulus is short lived. The results of studies of muscle protein synthesis, body composition, and strength in healthy young to middle aged humans tell a different tale: so far, no robust, credible study has been able to show clear effects of either medium to long term rhGH administration, alone or in combination with a variety of training protocols or anabolic steroids, on muscle protein synthesis, mass, or strength.

There are a number of ways in which an effect of GH on muscle growth may be detected. These include measurement of lean body mass by densitometry or by dual $x$ ray absorptiometry. As the rate of muscle protein turnover is relatively slow, it is relatively difficult to detect increases in muscle mass per se over periods shorter than three months using such static techniques, even if the rate of muscle growth is doubled. Measuring the rate of protein synthesis as the rate of incorporation of amino acids labelled with stable isotopes into muscle rather than simply the changes in muscle mass between two points is a much more sensitive method for determining the response of muscle. When this has been done in young healthy adults, no effect on muscle protein synthesis (or indeed on muscle mass measured by other means) has been detected. ${ }^{50}$ Furthermore, no effect has been detected in body builders and weightlifters. ${ }^{51}{ }^{52}$ Thus, at the very least, it appears that the evidence for a sustained anabolic effect of rhGH on muscle mass in normal healthy young men, trained or untrained, is extremely slim.

It has been suggested that, because GH secretion and thus IGF-I availability falls with age, rhGH administration should be beneficial in elderly men in decreasing adiposity and increasing lean body (principally muscle) mass. Indeed Rudman and coworkers ${ }^{53}{ }^{54}$ reported evidence that this was so; however, reproduction of these results by other workers has proven difficult. For example, in healthy middle aged to elderly men, administration of rhGH appears to cause no increase in muscle mass or strength ${ }^{55}$ unless it is associated with resistance training. Indeed it appeared that the benefits of exercise in terms of increased glucose tolerance were negated by rhGH in the elderly subjects. Supporting evidence of a lack of effects on elderly, but not particularly GH deficient, men was provided by Taffe and coworkers, ${ }^{57} 58$ who were unable to see any increases in strength or muscle mass or fibre characteristics after rhGH supplementation during a resistance exercise training programme. Recently, a wide ranging study of the effects of rhGH alone or combined with resistance training on muscle strength, power, muscle cross sectional area, and fibre size and mass in elderly men was unable to show any positive effects except in increasing the expression of myosin heavy chain type $2 \mathrm{x} .{ }^{59} 60$

Despite the excitement of the early days, there also appear to be no discernible effects on skeletal muscle mass or function in healthy elderly subjects, even with testosterone co-administration. The most recent paper available on this topic described the effects of testosterone, rhGH, or the two together in elderly men. ${ }^{61}$ The authors concluded that, after rhGH or rhGH together with testosterone, apart from the apparent increases in lean body mass of a type criticised above, there were only marginal increases in muscle strength and small increases in oxygen consumption.

It is possible that some workers have confused decreases in fat mass with increases in lean body mass, or have assumed muscle and lean body mass are equivalent. It may also be that rhGH administration causes increases in body water and connective tissue, which are registered as alterations in lean body mass. The overwhelming majority of reports suggesting that rhGH has an anabolic effect in adults come from studies of GH deficient patients.

A number of previous reviewers have made some similar points to those raised here. ${ }^{62-64}$

\section{DIFFERENTIAL DOSE EFFECTS}

Are scientists and doctors using too little hGH to see the effects that athletes achieve by using large doses? This is of course a possibility; by analogy, it was many years before scientists and doctors accepted that the anabolic effects of testosterone and its analogues were real-see, for example, the careful work of Forbes. ${ }^{65}$ Nevertheless, in my view the possibility is slight. Anecdotal evidence suggests that many hGH abusers, especially those taking the hormone without medical supervision, do inject supratherapeutic doses. However, in most of the studies in the literature, effects of hGH were also studied at greater than the therapeutic dose, and although these may well have been below the dosages used by abusers, they still resulted in serum concentrations of GH and IGF-I that were 3-6 times normal ${ }^{55} 56$ and that resulted in pronounced biological effects, such as increased lipolysis, altered carbohydrate metabolism, activation of the renin-angiotensin system, and water retention. It is difficult to believe that, even for effects that are not IGF-I mediated (such as the lipolytic effects), muscle tissue is IGF-I resistant to this extent.

Furthermore, when extremely large therapeutic doses of rhGH are used-for example, in the attempted treatment of wasting in HIV/AIDS - it appears to be much easier to induce diabetic symptoms than retention or recovery of lean body mass. ${ }^{29}{ }^{66}$ This, of course, may be a feature of a GH resistant syndrome, but it is odd that there is such a separation between biological effects of the same substance.

Nevertheless, it is relatively easy to see effects of other biological agents that do have effects on muscle protein turnover at blood concentrations that are observed biologically, and without using massive pharmacological doses. For example, insulin has substantial effects on protein synthesis and breakdown in muscle ${ }^{67-69}$ at concentrations seen after meals. As a further illustration, a modest rise in blood amino acids such as is seen after feeding causes a near doubling of muscle protein synthesis. ${ }^{67}{ }^{69}$ Why should a dose of rhGH, which can more than double serum IGF-I and cause considerable effects on body water, fat free mass, and nitrogen balance, ${ }^{50} 5156$ be insufficient to have an effect through IGF-I on muscle protein metabolism? It would, arguably, be a very unbiological pattern of behaviour.

Does the increased nitrogen retention often reported to be observed with rhGH administration ${ }^{50}$ not argue for an effect on muscle, the largest component of the lean body mass? Not necessarily. Apart from anabolic effects in viscera and skin, ${ }^{70}{ }^{71}$ rhGH has been reported to have anabolic effects on collagen metabolism, ${ }^{20} 72$ and even when bone is excluded from measurements of lean body mass using dual $x$ ray absorptiometry, the epimysial, endomysial, and perimysial collagenous components of skeletal muscle and connective tissue elements of skin may all show up as new lean body mass. A modest increase in skin, visceral protein and tissue (including muscle) collagen would translate into a sizeable positive nitrogen balance.

Such an effect on connective tissue in muscle would make the muscle no more capable of force generation but may promote resistance to injury or faster repair, which would be an advantage to an athlete. This may explain the anecdotally reported predilection of baseball players for abuse of testosterone and rhGH together. Unfortunately this possible synergism has never been studied under control circumstances in young men. Certainly co-administration of testosterone and rhGH has only a minor effect on strength in elderly men. ${ }^{61}$

If there were a threshold in the supraphysiological range for an anabolic effect of rhGH on muscle, it would be expected that patients with acromegaly would show true muscle hypertrophy. In fact, the lack of appreciably greater muscle mass per height as well as associated pathological changes (see later) argues against this idea. This is reinforced by the finding that 
transgenic mice overexpressing GH show no relative increase in muscle mass as a fraction of total body weight, and what muscle they have develops less force than expected on a weight basis. ${ }^{73}$

Thus, the balance of evidence seems to be heavily against an anabolic effect of rhGH on human muscle. It may seem that the only way to settle the question in the minds of champions of the use of rhGH is to carry out a dose-response study with large amounts of the hormone. This is easier said than done: we need to discover what amounts abusing athletes inject (it will always be easy to say that what was used was insufficient) to target an appropriate dose range while staying within normal ethical limits given the cardiovascular and metabolic hazards involved.

\section{THE DOWNSIDE OF rhGH ABUSE}

The acute administration of rhGH may have appreciably detrimental effects on performance. In fact, there is good evidence that acute administration of rhGH actually results in a decrease in exercise performance according to recent results obtained by Dr Kai Lange of the Danish Institute of Sports Medicine (personal communication). In these studies, healthy endurance trained athletes were unable to complete accustomed cycling tasks after administration of exogenous hGH. There is good evidence that hGH administration exacerbates the pronounced increase in lipolysis that occurs during exercise and, in addition, increases the production of lactate and protons by working muscles. The inevitable metabolic acidaemia and consequent reduction in the rate of glycogenolysis in muscle and liver could explain the acutely decreased performance. Furthermore, because of the effect of rhGH in decreasing glycogen storage in muscle and liver, it will make recovery from exercise more difficult. However, a bigger danger is probably the unphysiologically high fatty acidaemia, which could promote cardiac arrhythmia.

Chronic rhGH abuse is more dangerous. As most athletes are likely to be using suprapharmacological amounts, the correct model in which to look for such deleterious effects is not the adult GH deficient patient given replacement therapy, but patients suffering from acromegaly - that is, with an excess of GH secretion, often 100 times normal. These patients have poor exercise tolerance, which improves after treatment to decrease GH secretion. ${ }^{74}$ However, they show little evidence of true muscle hypertrophy in terms of creatinine to height ratios or muscle cross sectional areas, but often exhibit a number of myopathic features such as increased plasma creatine kinase, raised type 2 to type 1 muscle fibre areas, type 2 fibre atrophy, and myofilament loss as well as myopathic electrophysiological changes. ${ }^{75}$ Furthermore, patients with acromegaly have considerably increased rates of cardiovascular disease, diabetes, abnormal lipid metabolism, osteoarthritis, and breast and colorectal cancer. ${ }^{63}$ The concentrations of free fatty acids stimulated by exercise in these patients ${ }^{76}$ is in the range suggested by $\mathrm{Opie}^{77}$ to be a possible cause of sudden death from arrhythmia.

Another frightening problem is that, as supplies of bioengineered rhGH become more controlled, athletes are tempted to use the hormone obtained illegally from cadavers, ${ }^{78}$ risking the inevitably fatal Creutzfeldt-Jakob disease.

\section{WHY IS rhGH A DRUG OF ABUSE?}

If rhGH administration under controlled conditions has no stimulatory effect on muscle protein synthesis in adult humans, as the weight of evidence suggests, and confers no short term advantages as an acute ergogenic aid, why do athletes abuse it? There are probably three answers. Firstly, the effects on salt and water balance occur quickly, and athletes abusing rhGH are able to tell-for example, by proprioceptive effects in joints and muscles-that "something" has happened as a result of using it. This has a positive reinforcing effect, and

\section{Take home message}

The balance of evidence suggests that, in healthy adults, growth hormone does not build muscle and provides no athletic advantage. Growth hormone abuse, however, does cause disease. This message needs to be taken on board by coaches, team doctors, and potential abusers.

so they continue to take the drug. Secondly, there is no doubt that rhGH has what meat production experts call a "repartitioning" effect, in decreasing subcutaneous fat-the lipolytic effect being sufficiently powerful for athletes to perceive the resulting improvement in muscle definition (not actually muscle growth) relatively quickly. This is, no doubt, part of the reason rhGH is popular with body builders, but it is irrelevant to the argument about anabolic effects on muscle. In any case most elite athletes have low body fat, so it is doubtful whether any small increase in power to weight ratio as the result of loss of more fat could be significant in terms of increased performance.

Thirdly, there is the question of the disinformation on rhGH that envelopes young athletes. Part of this problem may, paradoxically, derive from the anti-doping authorities themselves. By ignoring the evidence that rhGH does not work in normal healthy subjects, the athletic establishment could be accused of effectively promoting its use. It is laudable to fund the development of a test that will be accurate, precise, and selective, so that those tempted to abuse rhGH will think twice. Sadly this has not happened, and instead large amounts of money have been spent in developing tests for GH that are probably insufficiently selective and sensitive and too cumbersome for practical use..$^{70}$ The failure was probably predictable, given the flawed strategy used in looking for biological indices (IGF-I and bone markers), which are too variable to satisfy the purpose. Investment in a proper education programme, which highlighted the available evidence, would have brought greater benefits.

\section{WHAT HAS TO BE DONE?}

We must tell athletes the truth: growth hormone does not "work" or at least not as they think it does and that it is associated with all kinds of immediate and long term hazardseverything from decreased performance to cancer. The benefits in terms of decreased subcutaneous fat are minor by comparison. The International Olympic Committee and the World Anti-Doping Agency and other national and international sporting bodies should sponsor programmes of research to settle outstanding important questions-for example, synergy of GH and anabolic steroids, dose-response relations-once and for all. All expenditure to improve tests for GH should be subordinate to the research and education programme, but in the meantime none of us, scientists, doctors, coaches, or sports bodies, should connive to suggest that this dangerous doping practice works. It almost certainly does not.

\section{REFERENCES}

1 Lewis UJ, Sinha YN, Lewis GP. Structure and properties of members of the hGH family: a review. Endocr J 2000:47(suppl):S1-8.

2 Hymer WC, Kraemer WJ, Nindl BC, et al. Characteristics of circulating growth hormone in women after acute heavy resistance exercise. Am J Physiol Endocrinol Metab 2001;281:E878-87.

3 Rosen CJ. Growth hormone and aging. Endocrine 2000;12:197-201.

4 Czeisler CA, Klerman EB. Circadian and sleep-dependent regulation of hormone release in humans. Recent Prog Horm Res 1999;54:97-130.

5 Ghigo E, Arvat E, Aimaretti G, et al. Diagnostic and therapeutic uses of growth hormone-releasing substances in adult and elderly subjects. Baillieres Clin Endocrinol Metab 1998;12:341-58.

6 Hunter WM, Fonseka CC, Passmore R. Growth hormone: important role in muscular exercise in adults. Science 1965;150:1051-3. 
7 Bloom SR, Johnson RH, Park DM, et al. Differences in the metabolic and hormonal response to exercise between racing cyclists and untrained individuals. J Physiol (Lond) 1976;258:1-18.

8 Consitt LA, Copeland JL, Tremblay MS. Endogenous anabolic hormone responses to endurance versus resistance exercise and training in women. Sports Med 2002;32:1-22.

9 Copeland JL, Consitt LA, Tremblay MS. Hormonal responses to endurance and resistance exercise in females aged 19-69 years. J Gerontol A Biol Sci Med Sci 2002;57:B158-65.

10 Pritzlaff CJ, Wideman L, Weltman JY, et al. Impact of acute exercise intensity on pulsatile growth hormone release in men. J Appl Physiol 1999:87:498-504

11 Pritzlaff-Roy CJ, Widemen L, Weltman JY, et al. Gender governs the relationship between exercise intensity and growth hormone release in young adults. J Appl Physiol 2002;92:2053-60

12 Kanaley JA, Weltman JY, Veldhuis JD, et al. Human growth hormone response to repeated bouts of aerobic exercise. J Appl Physiol 1997;83:1756-61.

13 Veldhuis JD, Liem AY, South S, et al. Differential impact of age, sex steroid hormones, and obesity on basal versus pulsatile growth hormone secretion in men as assessed in an ultrasensitive chemiluminescence assay. J Clin Endocrinol Metab 1995:80:3209-22.

14 Vahl N, Jorgensen JO, Jurik AG, et al. Abdominal adiposity and physical fitness are major determinants of the age associated decline in stimulated GH secretion in healthy adults. J Clin Endocrinol Metab 1996:81:2209-15.

15 Kanaley JA, Weatherup-Dentes MM, Jaynes EB, et al. Obesity attenuates the growth hormone response to exercise. J Clin Endocrinol Metab 1999;84:3156-61.

16 Maurer N. Metabolic effects of insulin like growth factor and growth hormone in vivo: a comparison. In: LeRoith D, Walker Z, Baker R, eds Insulin like growth factors. Georgetown, TX: Landes Bioscience, 2002:1-12.

17 Butler AA, Le Roith D. Control of growth by the somatropic axis: growth hormone and the insulin-like growth factors have related and independent roles. Annu Rev Physiol 2001;63:141-64.

18 Pell JM, Bates PC. The nutritional regulation of growth hormone action. Nutrition Research Reviews 1990:3:163-92.

19 Gregory JW, Greene SA, Jung RT, et al. Changes in body composition and energy expenditure after six weeks' growth hormone treatment [see comments]. Arch Dis Child 1991;66:598-602.

20 Lissett CA, Shalet SM. Effects of growth hormone on bone and muscle. Growth Horm IGF Res 2000;10(suppl B):S95-101.

21 Cameron CM, Kostyo JL, Adamafio NA, et al. The acute effects of growth hormone on amino acid transport and protein synthesis are due to its insulin-like action. Endocrinology 1988;122:471-4

22 Dardevet D, Sornet C, Attaix D, et al. Insulin-like growth factor-1 and insulin resistance in skeletal muscles of adult and old rats. Endocrinology 1994:134: 1475-84

23 Goldspink G. Changes in muscle mass and phenotype and the expression of autocrine and systemic growth factors by muscle in response to stretch and overload. J Anat 1999;194:323-34.

24 Gravholt $\mathbf{C H}$, Schmitz O, Simonsen L, et al. Effects of a physiological $\mathrm{GH}$ pulse on interstitial glycerol in abdominal and femoral adipose tissue. Am J Physiol 1999;277:E848-54.

25 Nielsen S, Moller N, Christiansen JS, et al. Pharmacological antilipolysis restores insulin sensitivity during growth hormone exposure. Diabetes 2001;50:2301-8.

26 Moller N, Jorgensen JO, Moller J, et al. Metabolic effects of growth hormone in humans. Metabolism 1995:44(suppl 4):33-6.

27 Bak JF, Moller N, Schmitz O. Effects of growth hormone on fuel utilization and muscle glycogen synthase activity in normal humans. Am J Physiol 1991;260:E736-42.

28 Clark RG, Mortensen D, Reifsynder D, et al. Recombinant human insulin-like growth factor binding protein-3 (rhlGFBP-3): effects on the glycemic and growth promoting activities of rhlGF-1 in the rat. Growth Regul 1993;3:50-2.

29 Lo JC, Mulligan K, Noor MA, et al. The effects of recombinant human growth hormone on body composition and glucose metabolism in HIV-infected patients with fat accumulation. J Clin Endocrinol Metab 2001;86:3480-7

30 Hoffman DM, Crampton L, Sernia C, et al. Short-term growth hormone $(\mathrm{GH})$ treatment of GH-deficient adults increases body sodium and extracellular water, but not blood pressure. J Clin Endocrinol Metab 1996:81:1123-8.

31 Moller J, Fisker S, Rosenfalck AM, et al. Long-term effects of growth hormone $(G H)$ on body fluid distribution in GH deficient adults: a four months double blind placebo controlled trial. Eur J Endocrinol 1999;140:11-16.

32 Moller J, Moller N, Frandsen E, et al. Blockade of the renin-angiotensin-aldosterone system prevents growth hormone-induced fluid retention in humans. Am J Physiol 1997;272:E803-8.

33 Rosenfeld RG, Attie K, Frane J, et al. Growth hormone therapy of Turner's syndrome: beneficial effect on adult height. J Pediatr 1998; 132:319-24

34 Fine RN, Sullivan EK, Tejani A. The impact of recombinant human growth hormone treatment on final adult height. Pediatr Nephrol 2000;14:679-81.

35 Germak JA. Growth hormone therapy in children with short stature: is bigger better or achievable? Indian J Pediatr 1996;63:591-7.

36 Haffner D, Schaefer F. Does recombinant growth hormone improve adult height in children with chronic renal failure? Semin Nephrol 2001;21:490-7.
37 Leger J, Garel C, Fiellestad-Paulsen A, et al. Human growth hormone treatment of short-stature children born small for gestational age: effect on muscle and adipose tissue mass during a 3 -year treatment period and after 1 year's withdrawal. J Clin Endocrinol Metab 1998;83:3512-16.

38 Gregory JW, Greene SA, Jung RT, et al. Metabolic effects of growth hormone treatment: an early predictor of growth response? Arch Dis Child 1993;68:205-9.

39 Subramanian S, Kellum JA. Limiting harm in the ICU. Minerva Anestesiol 2000;66:324-32.

40 Wolf SE, Barrow RE, Herndon DN. Growth hormone and IGF-I therapy in the hypercatabolic patient. Baillieres Clin Endocrinol Metab $1996 ; 10: 447-63$

41 Ziegler TR, Leader I. Adjunctive human growth hormone therapy in nutrition support: potential to limit septic complications in intensive care unit patients. Semin Respir Infect 1994;9:240-7.

42 Takala J, Ruokonen E, Webster NR, et al. Increased mortality associated with growth hormone treatment in critically ill adults. N Engl J Med 1999:341:785-92.

43 Butterfield GE, Thompson J, Rennie M, et al. Effect of rhGH and rhIGF-I treatment on protein utilization in elderly women. Am J Physiol 1997;272:E94-9

44 Cuneo RC, Salomon F, Wiles CM, et al. Histology of skeletal muscle in adults with $\mathrm{GH}$ deficiency: comparison with normal muscle and response to $\mathrm{GH}$ treatment. Horm Res 1992;37:23-8.

45 Cuneo RC, Salomon F, Wiles CM, et al. Growth hormone treatment in growth hormone-deficient adults. I. Effects on muscle mass and strength. J Appl Physiol 1991;70:688-94.

46 Salomon F, Cuneo RC, Hesp R, et al. The effects of treatment with recombinant human growth hormone on body composition and metabolism in adults with growth hormone deficiency. N EnglJ Med 1989;321:1797-803

47 Christ ER, Carroll PV, Russell-Jones DL, et al. The consequences of growth hormone deficiency in adulthood, and the effects of growth hormone replacement. Schweiz Med Wochenschr 1997;127:1440-9.

48 Fryburg DA, Gelfand RA, Barrett EJ. Growth hormone acutely stimulates forearm muscle protein synthesis in normal humans. Am J Physiol 1991;260:E499-504

49 Fryburg DA, Jahn LA, Hill SA, et al. Insulin and insulin-like growth factor-l enhance human skeletal muscle protein anabolism during hyperaminoacidemia by different mechanisms. J Clin Invest 1995:96:1722-9

50 Yarasheski KE, Campbell JA, Smith K, et al. Effect of growth hormone and resistance exercise on muscle growth in young men. Am J Physiol 1992;262:E261-7

51 Yarasheski KE, Zachwieja JJ, Angelopoulos TJ, et al. Short-term growth-hormone treatment does not increase muscle protein- synthesis in experienced weight lifters. J Appl Physiol 1993;74:3073-6.

52 Deyssig R, Frisch H, Blum WF, et al. Effect of growth hormone treatment on hormonal parameters, body composition and strength in athletes. Acta Endocrinol (Copenh) 1993;128:313-18.

53 Rudman D, Feller AG, Cohn L, et al. Effects of human growth hormone on body composition in elderly men. Horm Res 1991;36/suppl 1):73-81

54 Rudman D, Feller AG, Nagraj HS, et al. Effects of human growth hormone in men over 60 years old. N Engl J Med 1990;323:1-6.

55 Yarasheski KE, Zachwieja JJ. Growth hormone therapy for the elderly: the fountain of youth proves toxic. JAMA 1993;270:1694.

56 Yarasheski KE, Zachwieja JJ, Campbell JA, et al. Effect of growth-hormone and resistance exercise on muscle growth and strength in older men. Am J Physiol 1995;31:E268-76.

57 Taaffe DR, Jin IH, Vu TH, et al. Lack of effect of recombinant human growth hormone $(\mathrm{GH})$ on muscle morphology and $\mathrm{GH}$-insulin-like growth factor expression in resistance-trained elderly men. J Clin Endocrinol Metab 1996:81:421-5.

58 Taaffe DR, Pruitt L, Reim J, et al. Effect of recombinant human growth hormone on the muscle strength response to resistance exercise in elderly men. J Clin Endocrinol Metab 1994;79:1361-6

59 Lange $\mathbf{K H}$, Isaksson $\mathrm{F}$, Rasmussen $\mathrm{MH}$, et al. $\mathrm{GH}$ administration and discontinuation in healthy elderly men: effects on body composition, $\mathrm{GH}$-related serum markers, resting heart rate and resting oxygen uptake. Clin Endocrinol (Oxf) 2001;55:77-86.

60 Lange KH, Andersen JL, Beyer N, et al. GH administration changes myosin heavy chain isoforms in skeletal muscle but does not augment muscle strength or hypertrophy, either alone or combined with resistance exercise training in healthy elderly men. J Clin Endocrinol Metab 2002;87:513-23

61 Blackman MR, Sorkin JD, Munzer T, et al. Growth hormone and sex steroid administration in healthy aged women and men: a randomized controlled trial. JAMA 2002;288:2282-92.

62 Frisch H. Growth hormone and body composition in athletes. $J$ Endocrinol Invest 1999;22(suppl 5): 106-9.

63 Jenkins PJ. Growth hormone and exercise: physiology, use and abuse. Growth Horm IGF Res 2001;11 (suppl A):S71-7.

64 Yarasheski KE. Growth hormone effects on metabolism, body composition, muscle mass, and strength. Exerc Sport Sci Rev 1994;22:285-312.

65 Forbes GB. The effect of anabolic steroids on lean body mass: the dose response curve. Metabolism 1985;34:571-3.

66 Schauster AC, Geletko SM, Mikolich DJ. Diabetes mellitus associated with recombinant human growth hormone for HIV wasting syndrome. Pharmacotherapy 2000;20:1129-34.

67 Bennet WM, Connacher AA, Scrimgeour CM, et al. Euglycemic hyperinsulinemia augments amino acid uptake by human leg tissues during hyperaminoacidemia. Am J Physiol 1990;259:E 185-94. 
68 Biolo G, Fleming RYD, Wolfe RR. Physiologic hyperinsulinemia stimulates protein synthesis and enhances transport of selected amino acids in human skeletal muscle. J Clin Invest 1995;95:811-19.

69 Bennet WM, Connacher AA, Scrimgeour CM, et al. Increase in anterior tibialis muscle protein synthesis in healthy man during mixed amino acid infusion: studies of incorporation of $\left[1-{ }^{13} \mathrm{C}\right]$ leucine. Clin Sci 1989;76:447-54.

70 Wanke R, Hermanns W, Folger S, et al. Accelerated growth and visceral lesions in transgenic mice expressing foreign genes of the growth hormone family: an overview. Pediatr Nephrol 1991;5:513-21.

71 Wanke R, Milz S, Rieger N, et al. Overgrowth of skin in growth hormone transgenic mice depends on the presence of male gonads. J Invest Dermatol 1999;1 13:967-71.

72 Bollerslev J, Moller J, Thomas S, et al. Dose-dependent effects of recombinant human growth hormone on biochemical markers of bone and collagen metabolism in adult growth hormone deficiency. Eur J Endocrinol 1996;135:666-71.

73 Wolf $\mathbf{E}$, Wanke R, Schenck E, et al. Effects of growth hormone overproduction on grip strength of transgenic mice. Eur J Endocrinol 1995; 133:735-40.

74 Colao A, Cuocolo A, Marzullo P, et al. Is the acromegalic cardiomyopathy reversible? Effect of 5-year normalization of growth hormone and insulin-like growth factor I levels on cardiac performance. J Clin Endocrinol Metab 2001;86:1551-7.

75 Khaleeli AA, Levy RD, Edwards RH, et al. The neuromuscular features of acromegaly: a clinical and pathological study. I Neurol Neurosurg Psychiatry 1984;47:1009-15.

76 Johnson RH, Rennie M. Changes in fat and carbohydrate metabolism caused by moderate exercise in patients with acromegaly. Clin $\mathrm{Sci}$ 1973;44:63-71.

77 Opie LH. Fatty acids and sudden death. Am Heart J 1973;85:575.

78 Deyssig R, Frisch H. Self-administration of cadaveric growth hormone in power athletes. Lancet 1993;341:768-9.

79 Longobardi S, Keay N, Ehrnborg C, et al. Growth hormone (GH) effects on bone and collagen turnover in healthy adults and its potential as a marker of $\mathrm{GH}$ abuse in sports: a double blind, placebo-controlled study. The GH-2000 Study Group. J Clin Endocrinol Metab 2000;85:1505-12.

80 Wallace JD, Cuneo RC, Baxter R, et al. Responses of the growth hormone $(G H)$ and insulin-like growth factor axis to exercise, $G H$ administration, and $\mathrm{GH}$ withdrawal in trained adult males: a potential test for GH abuse in sport. J Clin Endocrinol Metab 1999;84:3591-601.

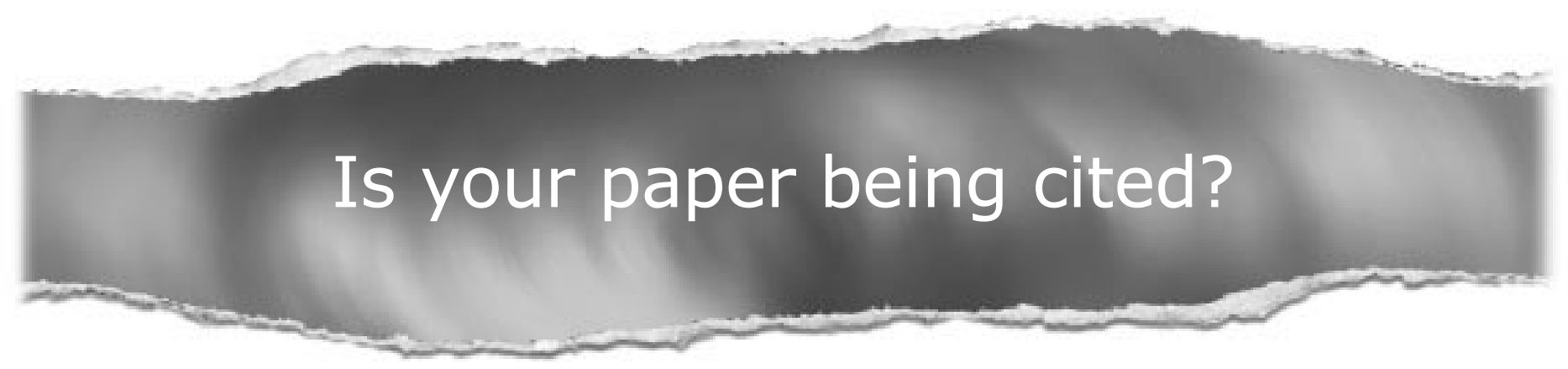

\section{CiteTrack service}

CiteTrack will alert you by email whenever new content in the British Journal of Sports Medicine or a participating journal is published

that matches criteria you want to track

Topics: Tell CiteTrack which words or subjects to watch for in new content

Authors: Be alerted whenever key authors you are following publish a new paper

Articles: Know whenever a paper of interest to you is referenced by another paper

\section{www.bjsportmed.com}

